\title{
Why Surgery for Incontinence and Prolapse Fails
}

\author{
Mickey M. Karram \\ Department of Obstetrics and Gynecology, University of Cincinnati School of Medicine, and \\ Department of Urogynecology and Reconstructive Pelvic Surgery, Good Samaritan Hospital and University of \\ Cincinnati, Ohio, USA
}

A recent study notes that in the United States a woman's lifetime risk of surgery for genuine stress incontinence or pelvic organ prolapse (POP) is $11.1 \%$, with nearly one third of surgery being performed for recurrences [1]. This would seem to indicate that a common approach to these conditions is surgery. Unfortunately, in a significant number of patients, the surgery is being redone or a secondary surgery is necessary. If one tries to delve into the question of why these operations fail, very little data are available. The primary reason for this is that surgeons have been reluctant to publish bad outcomes on their operations for incontinence and prolapse. While the literature is replete with new techniques and modifications that show excellent outcomes, in reality this is not the case. Until recently, few centers were equipped for and interested in assessing these surgical interventions with objective scientifically proven outcome parameters. This has been difficult to do because the outcomes of operations for urinary incontinence and POP are not easily addressed in a scientific fashion.

In the case of urinary incontinence, there are no standardized criteria for preoperative assessment, whether such evaluation is via urodynamic testing or otherwise. Although many surgeries are very similar, hundreds of modifications exist, which again make it difficult to assess the specific intervention. Most importantly, prior to determining whether an operation has failed or succeeded, one must define what a surgical cure is. To simply state that a patient no longer has stress incontinence is inadequate. On the other hand, to perform rigorous objective urodynamic studies and require not only subjective success, but also an improvement in objective anatomic and urodynamic parameters is probably unrealistic. I feel it is important to utilize standard quality-of-life assessment questionnaires as well as some form of objective analysis in these patients. Also, somehow there must be an assessment of the untoward effects of these operations. For example, if the patient has a retropubic urethropexy for stress incontinence, and is very satisfied with that aspect of the operation, but 3 months after the surgery has a large enterocele and vault prolapse which requires a second surgery, certainly her initial operation cannot be deemed a success.

This issue becomes even more difficult when one is attempting to assess outcomes for POP. These outcomes should be based on anatomic correction, visceral and sexual function. Unfortunately there are no standardized instruments that have been developed to specifically assess the outcome of POP. This, in my opinion, is an area that needs immediate attention.

The fact that prolapse and incontinence are quality-oflife conditions is a double-edged sword. Since the surgical intervention is very rarely a life and death situation, surgeons tend to be very cavalier about trying new techniques or materials that have not been through vigorous scientific testing to prove efficacy or improvement over

\begin{tabular}{ll}
\hline KARGER & ( ) 2001 S. Karger AG, Basel \\
Fax +41 613061234 & $0042-1138 / 01 / 0671-0012 \$ 17.50 / 0$ \\
$\begin{array}{l}\text { E-Mail karger@karger.ch } \\
\text { www.karger.com }\end{array}$ & $\begin{array}{l}\text { Accessible online at: } \\
\text { www.karger.com/journals/uin }\end{array}$
\end{tabular}

Mickey Karram, MD

Good Samaritan Hospital, Seton Center

375 Dixmyth Avenue

Cincinnati, OH 54220 (USA)

Tel. +1 513872 4171, Fax +1 513872 4498,E-Mail Mickey_Karram@trihealth.com 
more conventional techniques. I think there are numerous examples of this just in the past decade. To mention a few, there have been laparoscopic modifications, which allow a surgeon to perform procedures laparoscopically without requiring the ability to suture laparoscopically. These have included stapling devices, meshes, etc., that have really never undergone any rigorous testing prior to their use. A second example would be the entire bone anchor technology, which has been used very aggressively for anti-incontinence procedures both via the abdominal as well as vaginal route. Again, there has never been any scientific evidence to show that anchoring sutures or sling material into bone is more effective or durable than utilizing the lowest portion of the anterior abdominal fascia. Most recently, I see a move towards the utilization of intervening meshes at the time of vaginal prolapse surgery. Again, this is being advocated without any data showing benefit over conventional types of repairs.

Thus, in my opinion, there is a very urgent need to develop some standardized instruments to assess pelvic floor dysfunction including urinary incontinence, POP as well as defecatory and sexual dysfunction. These instruments should include a technique or method to assess complications and untoward outcomes not specifically related to why the surgery was being performed. Also, prospective randomized trials comparing new techniques and new materials to more conventional interventions must be done. As stated by a previous editor of the 'New England Journal of Medicine', 'if a study of the history of medicine reveals anything, it reveals that clinical judgement without the check of scientific controls is a highly fallible compass' [2]. If we do not begin to scrutinize and honestly assess our own surgical interventions, we will continue in the present state of constantly trying to improve on an overall satisfaction rate of somewhere between 60 and $85 \%$. This will bring about the development of more and more modifications, which will have more unknown and unintended effects that may lead to life-threatening complications that will go unreported. The end result is a lack of understanding of why we have failures after incontinence and prolapse surgery.

References $\quad 1$ Oellson AI, Smith VJ, Bergstrom JO, Colling
JG, Clark AI: Epidemiology of surgically man-
aged pelvic organ prolapse and urinary inconti-
nence. Obstet Gynecol 1997;89:501-506.
$2 \begin{aligned} & \text { Schafer A: The ethics of the randomized trial. } \\ & \text { (editorial). N Engl J Med 1982;307:719-724. }\end{aligned}$

